\title{
Perfil hematológico de bezerros da raça Nelore derivados de transferência nuclear de células somática adultas - clonagem
}

Patricia Baltagim Zacheo ${ }^{[]^{*}}$, João Morelli Júnior ${ }^{[a]}$, Bruno Fornitano Cholfe ${ }^{[a]}$, Igor Augusto Andreta Paiola ${ }^{[a]}$, Suellen Miguez Gonzalez ${ }^{[a]}$, Francisco Leydson Formiga Feitosa ${ }^{[b]}$, Guilherme Gonçalves Fabretti Santos ${ }^{[a]}$

\footnotetext{
[a] Hospital Veterinário Dr. Halim Atique, Centro Universitário de Rio Preto (Unirp), São José do Rio Preto, SP, Brasil

${ }^{[b]}$ Departamento de Clínica, Cirúrgica e Reprodução Animal, Curso de Medicina Veterinária, Universidade Estadual paulista (UNESP), Araçatuba, SP, Brasil
}

*Autor correspondente

e-mail: patriciabzacheo_medvet@hotmail.com

\section{Resumo}

A clonagem animal foi realizada pela primeira vez no ano de 1996, quando a ovelha Dolly ficou mundialmente conhecida. A clonagem de animais a partir de embriões reconstruídos com núcleos provenientes de células em diferentes estágios de diferenciação tem sido responsável pelo aparecimento de diversas anomalias durante a gestação e após o nascimento. No que concerne aos parâmetros hematimétricos, algumas discrepâncias vêm sendo caracterizadas nos animais clonados quando comparados aos animais originados por outros meios de concepção. Portanto, os exames laboratoriais são imprescindíveis para o estabelecimento do real quadro clínico do paciente e para elevar os índices de sucesso no atendimento desses animais. No presente estudo foram avaliados os aspectos hematológicos de 10 bezerros oriundos da técnica de clonagem e 6 bezerros frutos de fertilização in vitro (FIV). Todos os animais avaliados nasceram por meio da técnica de cesariana pela fossa paralombar esquerda. As amostras de sangue foram obtidas dos bezerros clonados e FIV ao nascimento, por meio de punção da veia jugular, usando sistema a vácuo, em um tubo siliconizado com anticoagulante com o uso de agulha para múltiplas coletas $\left(25 \mathrm{~mm}\right.$ x $8 \mathrm{~mm}$ ) do sistema Vacutainer ${ }^{\circledR}$. Essa amostra foi enviada ao laboratório para o processamento do hemograma. O volume globular (VG) foi obtido pelo método do microhematócrito; a contagem de hemácias e dosagem da hemoglobina foram realizadas por contador automático de células sanguíneas. A contagem de leucócitos totais foi realizada pelo método manual em câmara de Neubauer e a contagem diferencial de leucócitos e a avaliação da morfologia dos mesmos foram realizadas através de esfregaços sanguíneos. As variáveis foram submetidas à análise de variância, com medidas repetidas, sendo as médias comparadas por meio do teste de T pareado no nível de significância de 5\%. Para os bezerros clonados, os valores de hemácias, volume globular, hemoglobina, leucócitos, neutrófilos 
segmentados, linfócitos e monócitos foram, respectivamente: 6,12 $\pm 1,82 ; 26,63 \pm 8,558,17 \pm 2,69 ; 10,59 \pm$ 4,$37 ; 5408 \pm 4588 ; 4515 \pm 1651 ; 674 \pm 602$. E para os animais FIV 7,58 $\pm 2,11 ; 33,63 \pm 7,82 ; 10,35 \pm 2,95 ; 14,83$ $\pm 3,10 ; 11560 \pm 2701 ; 1639 \pm 837 ; 813 \pm 549$. A análise estatística mostrou que os valores de volume globular, neutrófilos segmentados e monócitos foram significativamente maiores nos bezerros FIV do que nos animais clonados. Já os valores de linfócitos foram significativamente maiores nos animais clonados. A contribuição do estudo da hematologia de bezerros logo após o nascimento ainda é crescente. Existem vários trabalhos na literatura que mostram uma grande discrepância entre os valores hematológicos. No entanto, a avaliação de tais parâmetros oriundos de animais concebidos através de cesariana ainda requer mais estudos. 